\title{
Fabrication of renewable resource based hyperbranched epoxy nanocomposites with MWCNT-polyaniline nanofiber-carbon dot nanohybrid as tough anticorrosive materials
}

\author{
A. Saikia, N. Karak ${ }^{*}$ \\ Advanced Polymer and Nanomaterial Laboratory, Department of Chemical Sciences, Tezpur University, Napaam, 784028 \\ Assam, India
}

Received 7 March 2019; accepted in revised form 9 June 2019

\begin{abstract}
Multi walled carbon nanotube (MWCNT)-polyaniline nanofiber-carbon dot (CD) nanohybrid was fabricated using in-situ polymerization of aniline in the presence of MWCNT and CD. Different spectroscopic techniques like Fourier transform infrared spectroscopy (FTIR) and ultraviolet-visible (UV-vis) spectroscopy were used to study the formation of the nanohybrid. The obtained nanohybrid was incorporated in different weight percentages in the hyperbranched epoxy derived from renewable resources like sorbitol and monoglyceride of castor oil. The formation of the nanocomposites was also verified using spectroscopic, microscopic and diffraction techniques. The thermosetting nanocomposites with uniform and stable dispersion of nanohybrid demonstrated excellent mechanical properties, such as tensile strength (69 MPa), elongation at break (45\%), scratch resistance $\left(>10 \mathrm{~kg}\right.$ ) and impact resistance $(16.7 \mathrm{~kJ} / \mathrm{m})$; good thermal stability (above $\left.264^{\circ} \mathrm{C}\right)$ and high chemical resistance. The anticorrosion performances of the cured nanocomposites were studied on mild steel plates in $3.5 \%$ sodium chloride $(\mathrm{NaCl})$ solution using potentiodynamic polarization method. The study showed that the nanocomposites with the highest percentage of the nanohybrid exhibited better anticorrosion performance (corrosion rate of $4.62 \cdot 10^{4} \mathrm{mpy}$ ) compared to the pristine thermoset. Thus, this study revealed that the hyperbranched epoxy with stable dispersion of the nanohybrid based nanocomposite can be potentially applied as a high performance anticorrosive material.
\end{abstract}

Keywords: nanocomposites, hyperbranched epoxy, polyaniline nanofiber, MWCNT, anticorrosion

\section{Introduction}

The carbon based nanomaterials have receieved tremendous attention in the past two decades because of their structure dependent tunable properties. One such carbon based nanostructured material is carbon nanotube(s) (CNT) [1]. CNT are usually rolled up sheets of two dimensional graphene with $\mathrm{sp}^{2}$ hybridized carbons $[1,2]$. These CNTs are extensively explored both theoretically as well as experimentally [1-4]. They can be either single walled or multi walled CNT (MWCNT) with diameters in the range of 20-40 nm and different chiral dimensions [5].
These CNTs were synthesized using different techniques like chemical vapor deposition (CVD) which can either be through plasma, thermally or catalytically and arc discharge methods [6-9]. These nanotubes have exceptional mechanical and electronic properties which are of great research interest for the fabrication of tough materials for advanced applications [10]. However, there are some disadvantages associated with the CNT. These are difficulties in dispersion and poor interfacial adhesion which resulted in serious complications to their further development [11]. Therefore, in order to resolve these 
problems, different functionalization routes have been developed [11].

Among the various types of methods, functionalization using conducting polymer is one of the most accepted alternatives. In this approach, polyaniline nanofiber (PANi) is the most obvious example. PANi has been widely used compared to other conducting polymers due to their tunable properties by using specific dopants, monomers or controlled polymerization processes. In addition, they are environmentally stable and possess good economic viability [12, 13]. However, the poor specific strength and compatibility issue of PANi necessitate the use of a binding matrix that results in the formation of composite or hybrid in the nanoscale for its commercial applications. Therefore, MWCNT proved to be one of the best supporting materials because of high mechanical strength, good chemical stability and high mesoporosity which provides better diffusibility of the reacting species [13-16]. Cochet et al. [17] synthesized $\mathrm{PANi} / \mathrm{CNT}$ nanocomposite through in-situ polymerization and studied the charge site-selective interaction by Raman spectroscopy. In another approach, Wang et al. [18] also reported the synthesis of PANi/ CNT nanocomposite by electrospinning and in-situ polymerization process. Literature also advocates the use of the MWCNT/PANi as the anticorrosive material. Kumar and Gasem [19] reported the use of functionalized MWCNT/PANi nanocomposites for corrosion protection of mild steel. In order to further improve the properties like electrical conductivity, anticorrosion etc. some other reactive species are incorporated in the nanocomposites like metal nanoparticles. In this context, Ghosh et al. [20] reported the use of $\mathrm{Ni}^{+}$and $\mathrm{H}^{+}$co-doped MWCNT/PANi nanocomposites with superior superconductivity compared to PANi. However, the utilization of metals as nanomaterials is inhibited due to their high toxicity and carcinogenic effects [21]. Therefore, the use of a non-toxic, eco-friendly and cost effective nanomaterial like carbon $\operatorname{dot}(\mathrm{s})(\mathrm{CD})$ may be a new alternative in the present scenario of research. $\mathrm{CD}$ are nanomaterials with low cytotoxicity, good biocompatibility, photostability and contain large number of surface functionalities compared to the conventional heavy metal based nanomaterials, quantum dots as well as organic dyes $[22,23]$. The application of $C D$ with large number of surface functionalities further improves the dispersion of the nanomaterials and hence, the properties of the materials can be enhanced.
Thus, the synergistic effects of PANi, MWCNT and $\mathrm{CD}$ can be employed in the fabrication of nanohybrids which will be of greater significance than the reported ones.

Among different types of polymers, epoxy resins have been extensively used in the preparation of polymer nanocomposites due to their high mechanical strength, adhesive strength, thermal and chemical stability [24]. However, the incorporation of conducting nanomaterials like PANi, MWCNT, graphene etc. results into good electrical and mechanical properties compared to the pristine epoxy resins [25]. In this milieu, researchers have developed myriad applications of these epoxy nanocomposites with conducting nanomaterials in the field of electromagnetic interference shielding, anticorrosive coatings, conducting adhesives etc. $[25,26]$. The combination of two or more such conducting nanomaterials as nanofillers in the epoxy matrix has been extensively explored for numerous advanced applications. Kumar et al. [26] reported the fabrication of epoxy/MWCNT nanocomposites by ultrasonication which showed enhancement of tensile strength up to $35 \%$ compared to the pristine epoxy. However, the flexibility of these nanocomposites is very low and therefore, their applications are limited. On the other hand, Imani et al. [27] prepared epoxy nanocomposites by incorporating PANi/MWCNT doped with para-toluene sulfonic acid (p-TSA). The nanocomposites showed improved electrical conductivity which is appropriately utilized for conducting adhesive application. The epoxies used in the preparation of these nanocomposites are mainly the commercially available epoxies which are derived from depleting petroleum resources that are costly and cause environmental problems and health hazard as they are responsible for skin irritation, inflammation etc. [28]. Also, they are highly brittle in nature which thereby limiting their applications. Therefore, renewable resource based epoxy resins proved to be a promising alternative for different applications. The major renewable resources which are extensively utilized in synthesis of epoxy resins are vegetable oils like soybean oil, castor oil etc., rosin, cashew seed liquid (CNSL) and lignin due to their easy availability and low cost characteristics [29]. These resins are highly flexible but have poor mechanical and thermal properties. On the other hand, the epoxy resins with hyperbranched architecture have demonstrated equivalent mechanical properties along with higher toughness compared 
to the commercially available epoxy resins [30]. Therefore, in this endeavor, renewable-resource based epoxy with hyperbranched architecture can be utilized for the fabrication of nanocomposites. The renewable branching moieties which are exploited by different research groups are mainly polyols with aliphatic backbone like derivatives of vegetable oils, polysaccharides or sugar alcohols. These hyperbranched epoxy resins are globular shaped, low viscosity polymers with large number of polar functional groups [30, 31]. Also, the presence of diverse functionalities in the nanohybrid interacts well with epoxy which can improve the dispersion, provide stability and increase the efficiency of the nanocomposites. The literature, however, remain totally silent in the use of CD decorated PANi/MWCNT nanohybrid for the fabrication of renewable resource based epoxy nanocomposites.

Thus, the present study is focused on the synthesis of nanohybrid through a facile in-situ polymerization of PANi in the presence of CD and MWCNT. Different weight percentages of nanohybrid were used to fabricate nanocomposites through an ex-situ polymerization technique. The nanohybrid and nanocomposites were well-characterized by using different spectroscopic, microscopic and diffraction techniques. Different properties of the nanocomposites such as mechanical, thermal, anticorrosion and chemical resistance were evaluated to judge their suitability to be used as anticorrosive materials.

\section{Experimental}

\subsection{Materials}

Ammonium peroxodisulfate (APS, Sisco Research Laboratories, India), epichlorohydrin (Sisco Research Laboratories, India), sodium hypochlorite (Merck Life Sciences Pvt. Ltd., India), hydrochloric acid ( $\mathrm{HCl})$ (Merck Specialties Pvt. Ltd., India), $\mathrm{NaCl}$ (Merck Specialties Pvt. Ltd., India) and sodium hydroxide $(\mathrm{NaOH})$ (Merck Specialties Pvt. Ltd., India) were used as received. Aniline (Sigma Aldrich, Germany) and tetrahydrofuran (Merck Specialties Pvt. Ltd., India) were freshly distilled prior to use. Castor oil (Sigma Aldrich, Germany) and sorbitol (HiMedia Laboratories Pvt. Ltd., India) were dried in vacuum prior to use. Bisphenol A (BPA, Sisco Research Laboratories, India) was recrystallized in toluene before use. Castor oil (Sigma Aldrich, Germany), glycerol (Merck Life Sciences Pvt. Ltd., India) and calcium oxide (Merck Life Sciences Pvt. Ltd., India) were dried in vacuum and used for the preparation of the monoglyceride.

\subsection{Preparation of nanohybrid}

The nanohybrid was prepared by the in-situ polymerization of aniline in the presence of MWCNT and $\mathrm{CD}$. The CD was prepared first by the hydrothermal method using rotten tomato as reported elsewhere [32].

Briefly, $0.20 \mathrm{M}$ aniline solution was prepared in $50 \mathrm{ml}$ of $1 \mathrm{M} \mathrm{HCl}$ solution. The initial procedure involved the dispersion of MWCNT and CD in $20 \mathrm{ml}$ of aniline solution by ultrasonication. The amount of MWCNT was taken in the weight ratio of $1: 1$, whereas $C D$ was taken as 1:3 with respect to the total weight of aniline present in $1 \mathrm{M} \mathrm{HCl}$ solution. Then, $20 \mathrm{ml}$ of $0.25 \mathrm{M}$ of ammonium peroxodisulfate (oxidant) was added into it and magnetically stirred at $0-5^{\circ} \mathrm{C}$. Immediately, as soon as the reaction started, $10 \mathrm{ml}$ of $5 \%$ sodium hypochlorite was added to the reaction mixture and the stirring was stopped. The reaction was allowed to stand for 30-35 min. A dark green suspension was formed indicating the formation of the nanohybrid. The suspension was washed several times by $1 \mathrm{M} \mathrm{HCl}$, distilled water followed by acetone and coded as MWPC.

For comparison purpose, a nanohybrid containing $\mathrm{CD}$ and PANi was also prepared from the reported method [32] and coded as PNC.

\subsection{Preparation of hyperbranched epoxy}

\subsubsection{Preparation of monoglyceride of castor oil}

The monoglyceride of castor oil required was prepared first by the reported method [31]. Briefly, castor oil and glycerol were taken together in a three necked round bottom flask in the mole ratio of 1:2 and mechanically stirred at $220 \pm 5^{\circ} \mathrm{C}$ under nitrogen atmosphere for $2 \mathrm{~h}$. After completion of the reaction the solubility was checked in methanol and dried in vacuum at $60-70^{\circ} \mathrm{C}$ before use.

\subsubsection{Preparation of epoxy resin}

The preparation of sorbitol based-monoglyceride of castor oil modified hyperbranched epoxy (SME) was carried out by following the procedure reported earlier, where bisphenol A, epichlorohydrin, sorbitol and monoglyceride of castor oil were reacted together at $110^{\circ} \mathrm{C}$ in the presence of $5 \mathrm{~N} \mathrm{NaOH}$ for $3 \mathrm{~h}$ [31]. The reactant was washed and dried at $70^{\circ} \mathrm{C}$ under vacuum. 


\subsection{Fabrication of nanocomposite}

The nanocomposites of MWPC and SME were fabricated in three different percentages of MWPC viz. $0.5,1$ and $1.5 \mathrm{wt} \%$ with respect to SME by an ex-situ fabrication technique. For the nanocomposite preparation, a stable dispersed solution of $0.025 \mathrm{~g}$ MWPC was prepared by ultrasonication for $20 \mathrm{~min}$ in an ultrasonic bath. Then, it was added to $5 \mathrm{~g}$ of epoxy resin containing $0.5 \mathrm{ml}$ of THF and magnetically stirred for $3 \mathrm{~h}$ at $45-50^{\circ} \mathrm{C}$. The addition of THF is only to facilitate easy mixing of the components. After completion of $3 \mathrm{~h}$, the resinous mixture was again ultrasonicated and coded as EMP0.5. Similarly, 1 and $1.5 \mathrm{wt} \%$ nanocomposites were also fabricated and coded as EMP1 and EMP1.5. The compositions of all the nanocomposites are tabulated in Table 1.

\subsection{Curing study}

The fabricated nanocomposites were cured by mixing poly(amido amine) hardener with epoxy equivalent of the resins in the weight ratio of 1:2. The homogenous mixture was cast on cleaned glass slides (dimensions: $75 \mathrm{~mm} \times 25 \mathrm{~mm} \times 1.3 \mathrm{~mm}$ ), degassed and kept at room temperature to note the touch free time. The films were then cured at $100^{\circ} \mathrm{C}$ in a convection oven, for a specified time interval in different stages. In the first stage, the films were taken out from the oven after curing for about $15 \mathrm{~min}$ and kept in a desiccator to attain room temperature. A needle was pierced into the films to check the extent of curing. A fully cured film is hard and difficult to pierce and if it is soft then the film was cured again for $10 \mathrm{~min}$ interval until it becomes hard. After that, the films were peeled off and a little piece of it was used for swelling test in THF for $24 \mathrm{~h}$. After $24 \mathrm{~h}$, the films were taken out and wiped to remove the residual solvent and the weight was checked. This process was repeated till the constant weight of the film was obtained. Then, the swelling percentage was calculated using Equation (1):

Table 1. Composition of different epoxy nanocomposites.

\begin{tabular}{|l|c|c|c|}
\hline \multirow{3}{*}{ Sample } & \multicolumn{3}{|c|}{ Components } \\
\cline { 2 - 4 } & \multirow{2}{*}{$\begin{array}{c}\text { SME } \\
\text { [g] }\end{array}$} & $\begin{array}{c}\text { Weight } \\
{[\%]}\end{array}$ & $\begin{array}{c}\text { Weight } \\
\text { [g] }\end{array}$ \\
\cline { 2 - 4 } & 5 & 0.5 & 0.025 \\
\hline EMP0.5 & 5 & 1.0 & 0.050 \\
\hline EMP1 & 5 & 1.5 & 0.075 \\
\hline EMP1.5 & 5 & 0 & 0 \\
\hline SME & 5 & &
\end{tabular}

Swelling $[\%]=\frac{W_{\mathrm{S}}-W_{\mathrm{D}}}{W_{\mathrm{D}}} \cdot 100$

where $W_{\mathrm{S}}$ and $W_{\mathrm{D}}$ are the weights of the swelled and dried films respectively. If the swelling percentages lie in between $20-30 \%$ then the films are cured completely. The curing time is increased further if the swelling percentage is above $30 \%$. Conversely, the time is reduced if the swelling percentage is below $20 \%$ otherwise the films become brittle in nature. The cured films were then used for different analyses and testing of mechanical, thermal, chemical resistance etc. properties.

\subsection{Instrumentation}

The fabricated nanocomposites were characterized by Fourier transform infrared (FTIR) spectrophotometer (Model: Impact 410, Nicolet, Madison, USA) by using $\mathrm{KBr}$ pellets in the range of $500-4000 \mathrm{~cm}^{-1}$. The presence of crystallinity or amorphous nature of the nanocomposites was evaluated from X-ray diffractogram (XRD) over a range of $2 \theta=10-90^{\circ}$ (Model: D8 FOCUS, Bruker AXS, Germany). High resolution transmission electron microscope (HRTEM), (Model: JEM-2100, JEOL, Japan) was used to analyze the morphological features using $\mathrm{Cu}$ grid of 400 mesh. The nanohybrid was sonicated by using UP200S (Hielscher, Germany) ultrasonic processor with a $3 \mathrm{~mm}$ tip diameter standard sonotrode at $60 \%$ amplitude. The thermogravimetric (TG) analyzer, TGA 4000 (Perkin Elmer, USA) was used for thermostability study under nitrogen atmosphere (flow rate of $30 \mathrm{ml} \cdot \mathrm{min}^{-1}$ ), in the temperature range $32-720^{\circ} \mathrm{C}$ (heating rate: $10^{\circ} \mathrm{C} \cdot \mathrm{min}^{-1}$ ). The mechanical properties of the cured thermosetting nanocomposites like tensile strength and elongation percentage were evaluated by universal testing machine (UTM), (Model: WDW10, Jinan, China) using a load cell of $500 \mathrm{~N}$ at $20 \mathrm{~mm} \cdot \mathrm{min}^{-1}$ cross head speed. The adhesive strengths of the thermosets were also evaluated by UTM machine on metal-metal $(78 \mathrm{~mm} \times$ $25 \mathrm{~mm} \times 0.50 \mathrm{~mm}$ ) substrates with a load of $10 \mathrm{kN}$ at a crosshead speed of $50 \mathrm{~mm} \cdot \mathrm{min}^{-1}$. The scratch resistance was tested by a scratch hardness tester (Sheen Instruments Pvt. Ltd., UK) and the impact resistance was tested by the standard falling ball method (S.C. Dey \& Co., India). The chemical resistance of the cured thermosets was checked in different chemical environments such as aqueous $\mathrm{NaCl}(15 \%)$, aqueous $\mathrm{NaOH}(5 \%)$, aqueous $\mathrm{HCl}(10 \%)$ and fresh water for 
a period of 30 days and the weight losses of these thermosets were checked. The electrochemical corrosion analysis of the thermosets was checked on bare mild steel strips (BS) of dimensions $25 \mathrm{~mm} \times 25 \mathrm{~mm} \times$ $0.57 \mathrm{~mm}$. For this test, nanocomposites of each composition was mixed with appropriate amount of hardener and cast on the cleaned BS surface on the both sides. The covered BS were cured at elevated temperature for an optimum period of time. The anticorrosion analysis of the cured and coated MS were performed in a conventional three electrode system using Autolab PGSTAT302N (Metrohm, UK) at room temperature. Here, $\mathrm{Ag} / \mathrm{AgCl}$ electrode saturated with $\mathrm{KCl}$ used as the reference electrode, $\mathrm{Pt}$ wire as the counter electrode and coated BS plate as the working electrode. The electrolyte used for the study was 3.5\% $\mathrm{NaCl}$ and $3.5 \% \mathrm{HCl}$ solutions.

\section{Results and discussions}

\subsection{Preparation of MWPC nanohybrid and its nanocomposite}

The MWPC nanohybrid was synthesized using insitu polymerization of aniline in the presence of

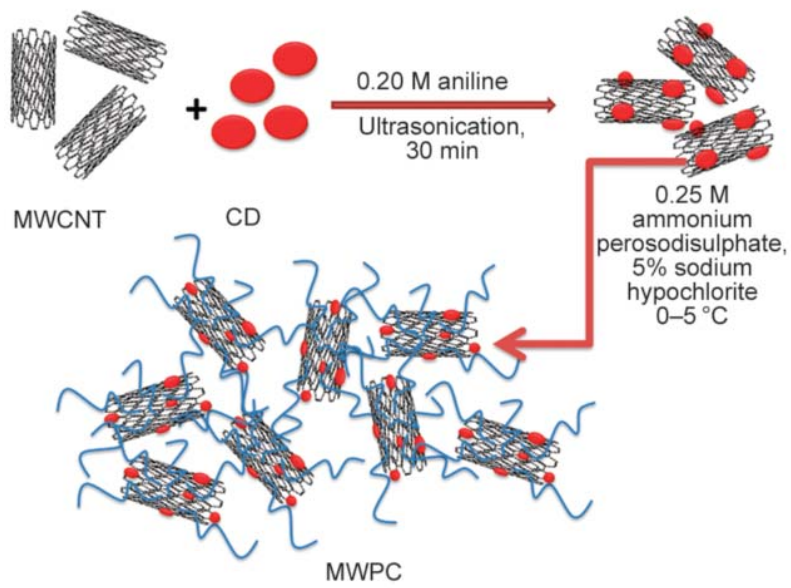

Figure 1. Probable schematic route for MWPC nanohybrid preparation.

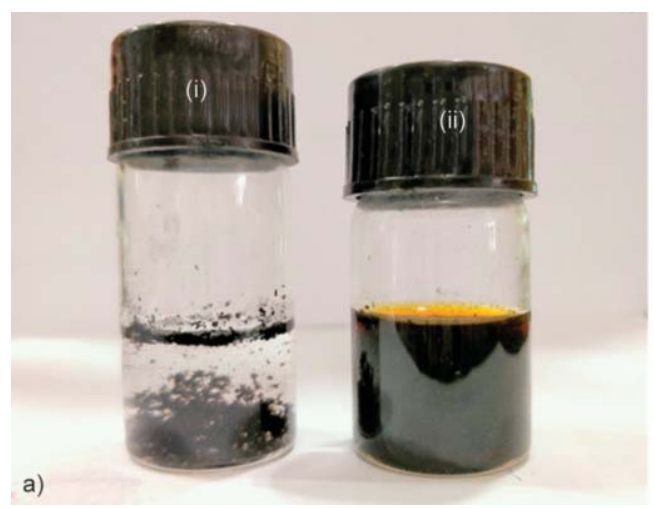

MWCNT and CD. A probable mechanistic route of this process is outlined in Figure 1. At the initial stage, MWCNT and CD were ultrasonicated in $0.20 \mathrm{M}$ of acidic solution of aniline. MWCNT are highly agglomerated due to high surface energy that results into strong van der Waals forces of attraction between them. The ultrasonication forces are necessary because they help in exfoliation and proper dispersion of agglomerated nanotubes in the solution. MWCNT acts as the electron acceptor which forms weak charge transfer complex with anilium ions consisting of electron lone pairs. Also, the mesopores present in the nanotube help in the diffusion process of the ions. Hence, a heterogeneous system was formed. The addition of oxidant immediately initiates polymerization of the anilium ions on the surface of MWCNT, which is much faster compared to the ions present in the solution phase [16]. The role of sodium hypochlorite addition to the reaction mixture is to promote the fibril formation along the axes of PANi to control the formation of fibers with large aspect ratio [33]. Further, the addition of CD improves the dispersion of MWCNT in the aniline solution as shown in Figure 2a. CD are spherical nanoparticles consisting of graphitic structure with large number of polar peripheral groups like $-\mathrm{OH},-\mathrm{COOH}$ etc. These peripheral groups stabilize the MWCNT through polar-polar and $\pi-\pi$ interactions $[32,34$, 35]. Thus, the polymerization of aniline proceeds uniformly in MWPC as compared to other MWCNT/ PANi systems.

The dispersion of the MWPC nanohybrid was checked and it was found that a stable dispersion was formed in polar aprotic solvents like dimethylformamide (DMF), dimethyl acetamide (DMAc), dimethyl sulfoxide (DMSO), tetrahydrofuran (THF) etc. which is evident from the fact that the highly conjugated

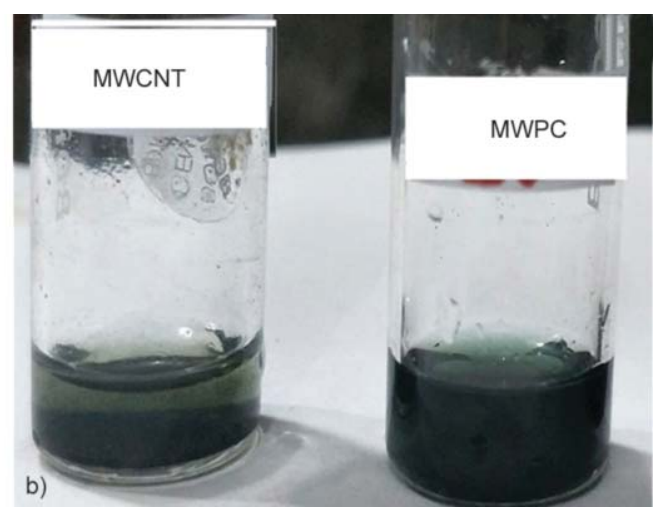

Figure 2. (a) Dispersion of (i) MWCNT and (ii) MWCNT-CD in aniline solution; (b) Dispersion of MWCNT and MWPC in DMF. 
systems of the nanohybrid demonstrated electrostatically strong interactions with the solvents [36,37]. However, the pristine MWCNT before modification was unable to remain dispersed in any organic solvent, even for a fraction of time. The dispersions of MWPC and MWCNT in DMF are shown in Figure $2 \mathrm{~b}$. The dispersions were utilized for the study within $48 \mathrm{~h}$ in each case where the dispersion remains stable. However, the dispersion can remain stable up to $72 \mathrm{~h}$. After that, agglomeration starts to form and dispersion became unstable.

The nanocomposite was prepared by an ex-situ polymerization technique. Here, the sorbitol and monoglyceride of castor oil based SME was used as the matrix and MWPC was used as the reinforcing agent. The formation route of the nanocomposite is outlined in Figure 3. SME contains sorbitol which is an aliphatic polyol and acts as the branch generating unit. The monoglyceride of castor oil is used which has also aliphatic moieties that provides flexibility to the matrix. SME has globular shape and non-entangled structure with abundant surface functionalities [31]. These provide suitable environment for interaction of the nanohybrid that instigated better dispersibility and good compatibility in the epoxy matrix which resulted in substantial impact on the ultimate properties of the nanocomposites. Therefore, MWPC was ultrasonicated for sufficient time so that a stable dispersion was formed in THF without any agglomeration, prior to addition into the polymer matrix. Also, the epoxy resin was mixed with minimum amount of THF in order to accomplish smooth mixing and uniform dispersion of MWPC in SME matrix. Further, mechanical shear force for intimate mixing was applied followed by ultrasonication. Moreover, in order to study the effect of MWPC on the properties of the nanocomposites different weight percentages viz. $0.5,1$ and $1.5 \%$ were mixed separately with the epoxy matrix [38].

\subsection{Characterization}

The FTIR spectra of MWPC, PANi, SME and EMP0.5, EMP1 and EMP1.5 support the proposed structural functionalities of the respective nanohybrids and nanocomposites (Figure $4 \mathrm{a}$ and $4 \mathrm{~b}$ ). The spectrum of MWPC demonstrated the presence of

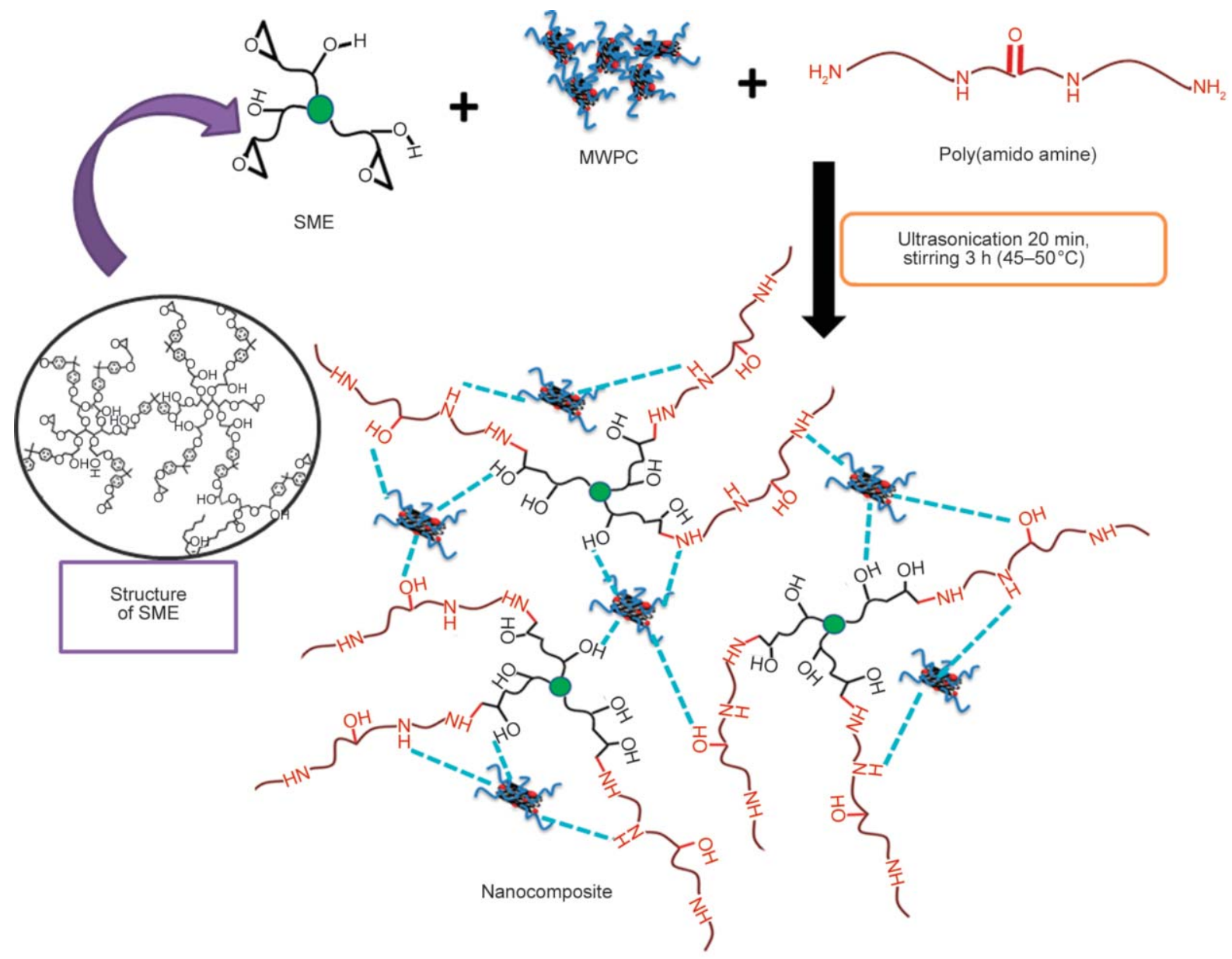

Figure 3. Schematic route of the ex-situ fabrication for the nanocomposites. 
characteristic bands at 3443 and $3188 \mathrm{~cm}^{-1}$ corresponding to the $-\mathrm{N}-\mathrm{H}$ and $-\mathrm{O}-\mathrm{H}$ stretching frequencies. Thus, the amine and hydroxyl groups are present in the structure of the nanohybrid [32]. In case of FTIR spectrum of PANi, the stretching frequencies of $3442,1556,1461$ and $1376 \mathrm{~cm}^{-1}$ correspond to $-\mathrm{N}-\mathrm{H},-\mathrm{C}=\mathrm{C}-$ of quinoid and benzoid rings and $-\mathrm{C}-\mathrm{N}$ stretching modes respectively [12]. However, in the nanohybrid of PANi with $\mathrm{CD}$, the peaks at 1731,1640 and $1497 \mathrm{~cm}^{-1}$ correspond to $-\mathrm{C}=\mathrm{O}-$ of carbonyl, $-\mathrm{C}=\mathrm{C}-$ of benzoid and quinoid and $-\mathrm{C}-\mathrm{N}$ stretching frequencies respectively; as reported earlier [32]. The additional frequencies of $-\mathrm{O}-\mathrm{H}$ and $-\mathrm{C}=\mathrm{O}$ stretchings also appeared at 3188 and $1725 \mathrm{~cm}^{-1}$ due to the presence of CD [32]. These stretching frequencies of MWPC have shifted to lower wavenumbers of $1718(-\mathrm{C}=\mathrm{O}), 1636(-\mathrm{C}-\mathrm{N})$ and $1494(-\mathrm{C}=\mathrm{C}-) \mathrm{cm}^{-1}$ due to the increase in conjugation in the structure as a result of MWCNT incorporation in the system [20]. On the other hand, the stretching frequencies of $-\mathrm{N}-\mathrm{H}$ at $3443 \mathrm{~cm}^{-1}$ and imine deformation at $1191-1051 \mathrm{~cm}^{-1}$ showed a blue shift compared to PANi and CD based nanohybrid as reported earlier (Imine deformation: 1178$1044 \mathrm{~cm}^{-1}$ ) [32]. This is due to the stabilization of PANi on the surface of MWCNT through $\pi-\pi$ interaction and van der Waals interaction which is reflected by the shortening of the $-\mathrm{N}-\mathrm{H}$ bond in the spectrum.

The FTIR spectrum of SME demonstrates the overlap of $-\mathrm{O}-\mathrm{H}$ with $-\mathrm{N}-\mathrm{H},-\mathrm{C}-\mathrm{H}$ and $-\mathrm{C}=\mathrm{C}-$ stretching frequencies at $3460,2967,1614-1516 \mathrm{~cm}^{-1}$. These bands were shifted to 3302,2930 and $1607-$ $1498 \mathrm{~cm}^{-1}$ respectively in the nanocomposites. This red shift indicates the interaction of the epoxy resin with the benzoid and quinoid structures of PANi, graphitic structures of CD and MWCNT, present in MWPC. Also, the diminishing oxirane ring at
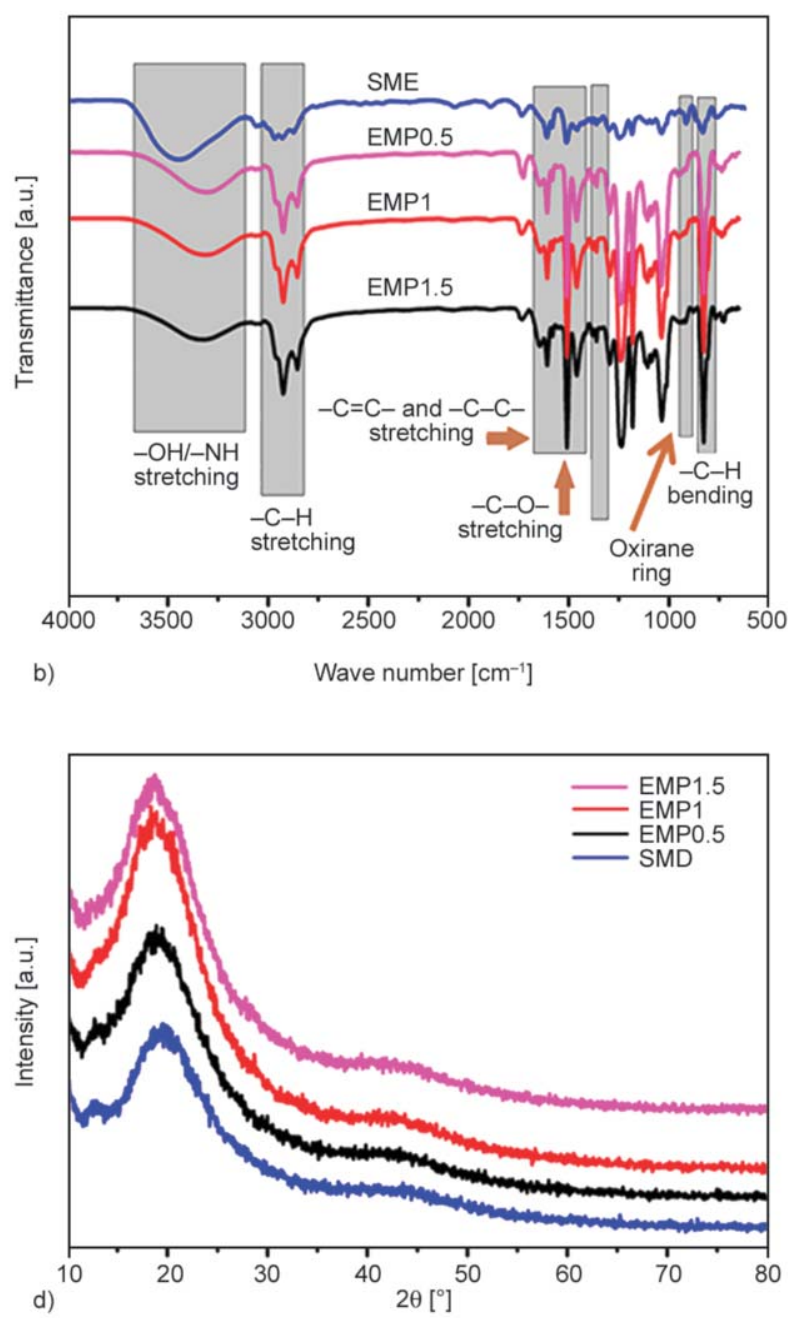$$
\text { d) }
$$
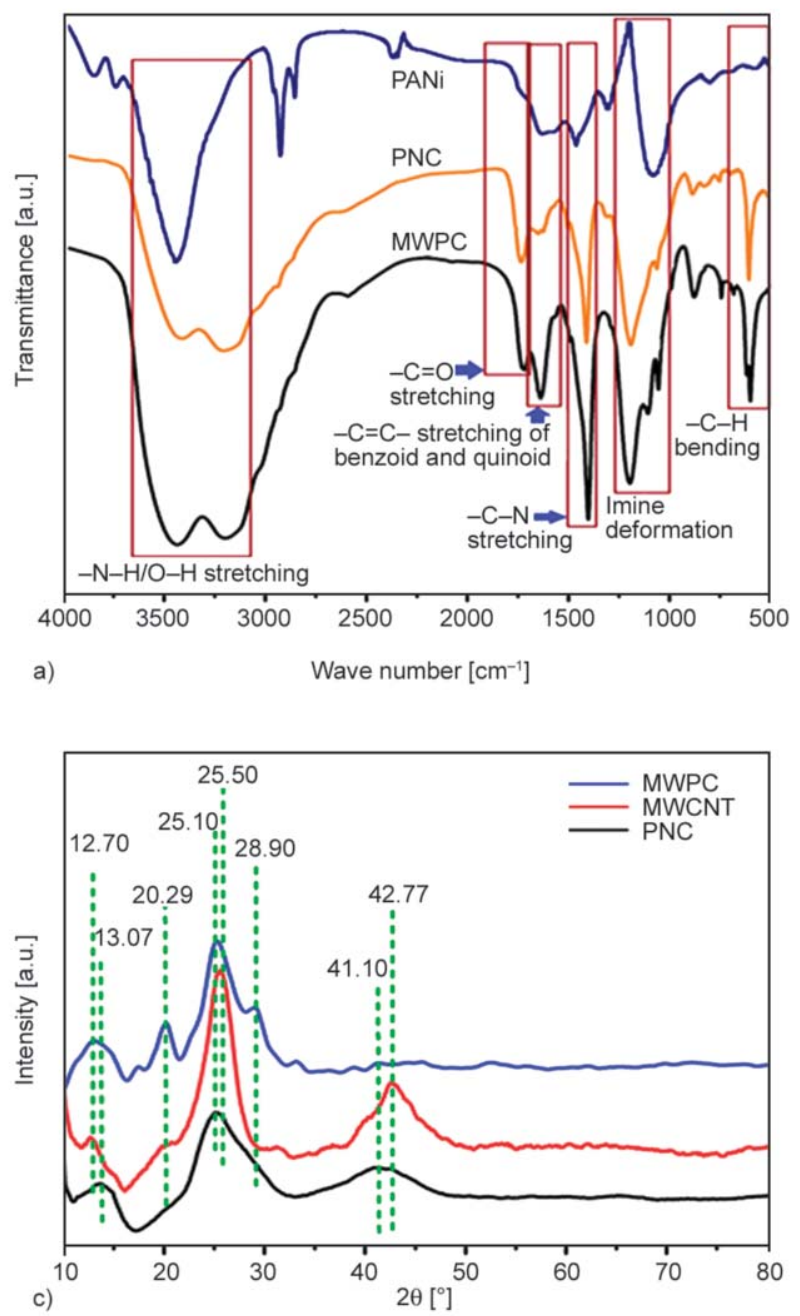

Figure 4. FTIR spectra of the (a) MWPC, PNC (nanohybrid of PANi and CD) and PANi; (b) SME and EMP0.5 and XRD patterns of (c) MWPC, MWCNT and PNC (nanohybrid of PANi and CD); and (d) EMP0.5, EMP1, EMP1.5 and SME. 
$915 \mathrm{~cm}^{-1}$ reflects the utilization of this group in curing of the resin to form a three dimensional network structure [31].

The XRD patterns of MWPC, (Figure 4c, Table 2), showed the characteristic peaks at $2 \theta=13.07,20.29$, 25.10 and $28.90^{\circ}$ corresponding to Bragg reflection planes of (011), (002), (200) and (022) of the emeraldine salt form of PANi and MWCNT and $d$-spacing values $=3.08,3.54,4.37,6.75$, respectively [32]. The appearance of the (002) and (022) peaks in the diffraction pattern of MWPC may be due to the strong interactions between $\mathrm{CD}$ and MWCNT that resulted into some distortions in the orientations of parallel and perpendicular chains compared to PNC $[32,34]$. The peak at $2 \theta=42.7$ ((100) plane) is due to the reflection of the graphitic like structure which diminishes in MWPC due to the $\pi-\pi$ interaction between MWCNT, PANi and CD [35]. This interaction is also proved by the shifting of the $2 \theta$ values compared to MWCNT as shown in Table 3.

In case of the nanocomposites (Figure 4d), a broad reflection was observed for all the compositions at $2 \theta=19.10$ due to the interaction of MWPC with the polymeric chains of the matrix. The XRD patterns of the matrix demonstrated the amorphous nature of the polymer. The diminished peaks of MWPC in the diffraction pattern of nanocomposites resulted due to the masking effect of the polymer matrix. However, the peak intensities have increased with the increase of MWPC content in the polymer matrix which is

Table 2. $2 \theta$ values, Bragg's diffraction planes and d-spacing of MWPC, MWCNT and PNC.

\begin{tabular}{|l|c|c|c|}
\hline \multirow{3}{*}{ Sample code } & $\begin{array}{c}\mathbf{2 \theta} \\
{\left[{ }^{\circ}\right]}\end{array}$ & $\begin{array}{c}\text { Bragg's reflection } \\
\text { planes }\end{array}$ & $\boldsymbol{d}$-spacing \\
\hline \multirow{4}{*}{ MWPC } & 28.90 & $(022)$ & 3.08 \\
\cline { 2 - 4 } & 25.10 & $(200)$ & 3.54 \\
\cline { 2 - 4 } & 20.29 & $(002)$ & 4.37 \\
\cline { 2 - 4 } & 13.07 & $(011)$ & 6.75 \\
\hline \multirow{4}{*}{ MWCNT } & 42.77 & $(100)$ & 2.11 \\
\cline { 2 - 4 } & 25.50 & $(200)$ & 3.49 \\
\cline { 2 - 4 } & 12.70 & $(011)$ & 6.96 \\
\hline \multirow{3}{*}{ PNC } & 41.10 & $(100)$ & 2.20 \\
\cline { 2 - 4 } & 25.10 & $(200)$ & 3.54 \\
\cline { 2 - 4 } & 13.50 & $(011)$ & 6.55 \\
\hline
\end{tabular}

Table 3. Curing time and swelling percentages of SME, EMP0.5, EMP1 and EMP1.5.

\begin{tabular}{|l|c|c|c|c|}
\hline \multicolumn{1}{|c|}{ Parameters } & SME & EMP0.5 & EMP1 & EMP1.5 \\
\hline Curing at $100^{\circ} \mathrm{C}[\mathrm{min}]$ & $45 \pm 5$ & $35 \pm 1$ & $27 \pm 2$ & $20 \pm 5$ \\
\hline Swelling $\quad[\%]$ & 27 & 26 & 25 & 24 \\
\hline
\end{tabular}

due to the presence of strong secondary interactions between MWPC and nanocomposites resulted in stacking of the polymeric chains of MWPC with the polymer matrix in EMP1 [16, 36, 38].

\subsection{Curing study}

The resinous materials were transformed into the solid three-dimensional network structure through the curing reactions. In this process, the three membered strained epoxide rings opens up by the labile electrons of the amine groups present in the poly (amido amine) hardener when cured at a temperature of $100^{\circ} \mathrm{C}$. The study showed that the curing time decreased with the increase in the percentage of the nanomaterial in the matrix. This is because of the presence of strong polar-polar interactions between the polar functionalities of the nanohybrid with the free- $\mathrm{OH}$ groups of the hyperbranched epoxy matrix [31]. Moreover, the curing process initiates with basicity of the medium offered by the hardener which further enhances with the addition of the polymeric chains of PANi. The presence of MWCNT and CD in the nanohybrid further provides adequate number of surface functionalities for better interaction with the hyperbranched structure of SME. The extent of optimum curing was verified by the swelling percentage of the thermosets. In order to further verify the curing temperature, DSC test of EMP1 was performed which showed that the exothermic peak appeared at $90^{\circ} \mathrm{C}$. For this study, $0.002 \mathrm{~g}$ of the sample was taken in a metal pan of $\left(1 \mathrm{~mm}^{2}\right)$ where the thickness of the film is very low compared to the films demonstrated in Table 3 which were cast in glass slides of thickness $0.54-0.75 \mathrm{~mm}$. Therefore, the curing temperatures of these films were chosen as $100^{\circ} \mathrm{C}$. Also, the curing reaction involves the release of volatiles, so high temperature also accounts for the easy release of the entrapped molecules. Actually, the hyperbranched polymeric systems are globular shaped where there is possibility of solvent entrapment which may result into variation of mechanical and thermal properties. However, THF is a low boiling solvent which was evaporated by drying under vacuum and further when cured at $100^{\circ} \mathrm{C}$. Therefore, there is no chance of presence of any residual THF in the polymeric film.

The curing time was determined by checking the swelling values. The curing time as well as their swelling percentages were evaluated and tabulated in Table 3. The optimized curing time was chosen 
only when the swelling percentages of the films were found in between $20-30$ percentages. From the table, it is observed that EMP1.5, containing the highest percentage of MWPC, exhibited the lowest curing time and swelling percentage compared to EMP0.5, EMP1 and SME, which indicates the formation of a highly crosslinked structure.

\subsection{Optical properties}

The sensitivity of the nanomaterial towards the size, state of agglomeration and shape can be identified and characterized using UV-vis spectroscopy. UVvis absorbency of MWPC (Figure 5a) is distinctly different from the absorbencies of PANi or even PNC [32]. The peak at $297 \mathrm{~cm}^{-1}$ of MWPC corresponds to $\pi-\pi^{*}$ transition. The red shift is due to the presence of long conjugation of the graphitic structure of MWCNT and CD. Also, the strong interaction between the conjugated structure of PANi and graphitic structure of MWCNT through the quinoid ring results an extended conjugation and hence, the red shift of band position of exciton transition from
$774 \mathrm{~nm}$ of PANi to $813 \mathrm{~nm}$ of MWPC was observed $[16,32]$. However, the band at $450 \mathrm{~nm}$ due to $\pi-\pi^{*}$ transition of the conjugated structure of PANi also showed a blue shift to $422 \mathrm{~nm}$ for MWPC. This is due to the shortening of $-\mathrm{N}-\mathrm{H}$ bond in the benzoquinoid structure as evident from the FTIR studies.

\subsection{Morphological studies}

The morphological characteristics of MWPC and the nanocomposites were studied by TEM images analyses. The dispersion of the nanohybrid in the polymer matrix of EMP0.5 nanocomposite was also studied by TEM images which showed uniform dispersion Figure $5 \mathrm{~b}$. Since the TEM images of the nanocomposites only show the dispersion of the nanomaterial in the matrix, hence, only one representative nanocomposite is studied and shown in Figure 5b. The EDXTEM spectrum of MWPC was also studied and presented in Figure $5 \mathrm{c}$. From the spectrum, it is observed that peaks at $0.3,0.4$ and $0.6 \mathrm{keV}$ are attributed to the carbon $(\mathrm{C})$, oxygen $(\mathrm{O})$ and nitrogen $(\mathrm{N})$. The atomic $\%$ and weight $\%$ of these elements are shown

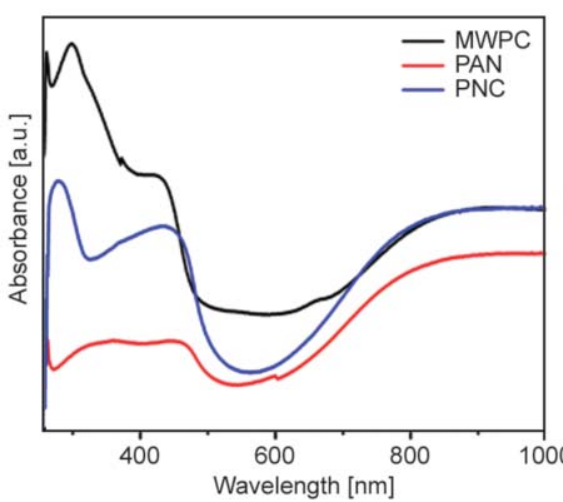

a)

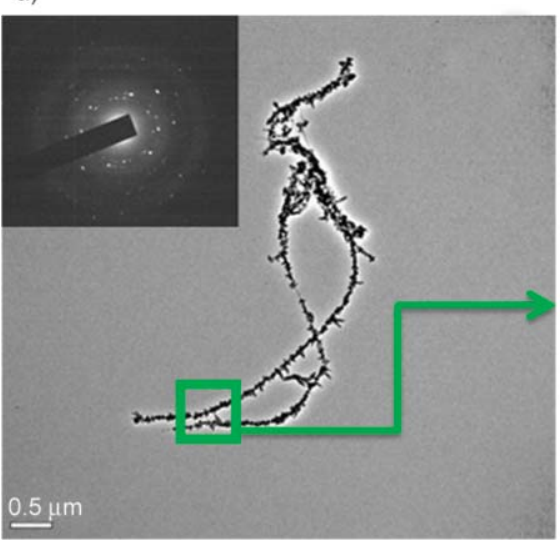

d)

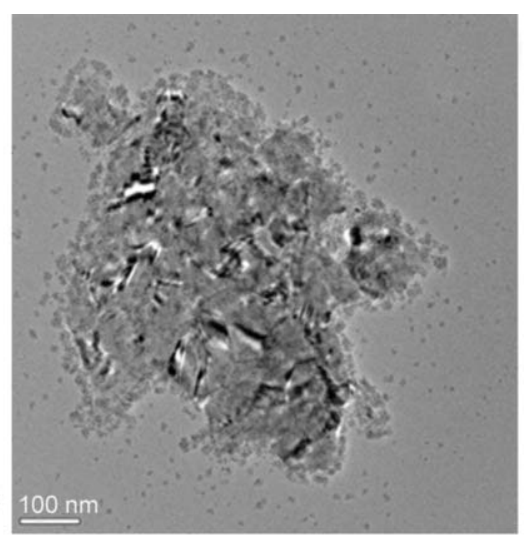

b)

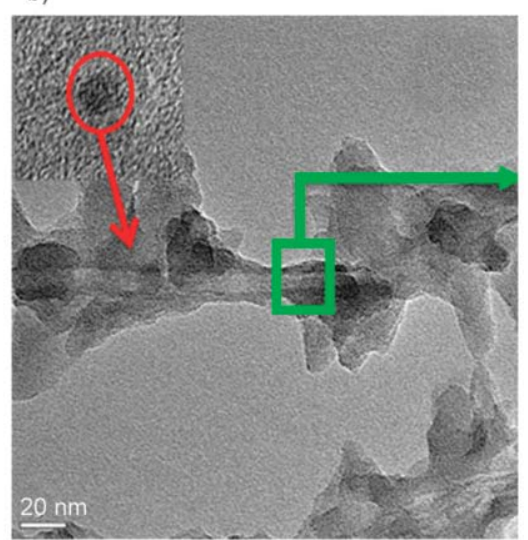

e)

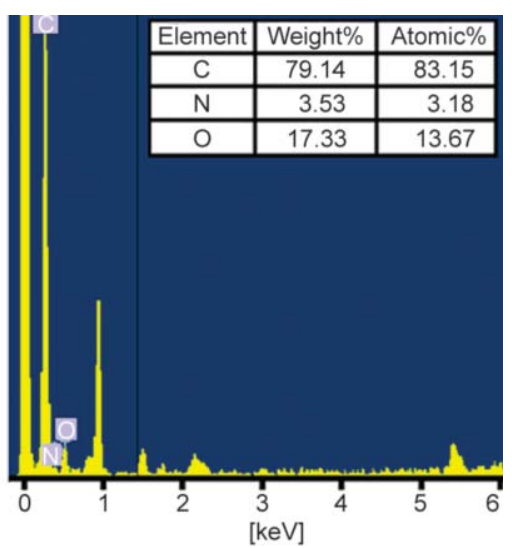

c)

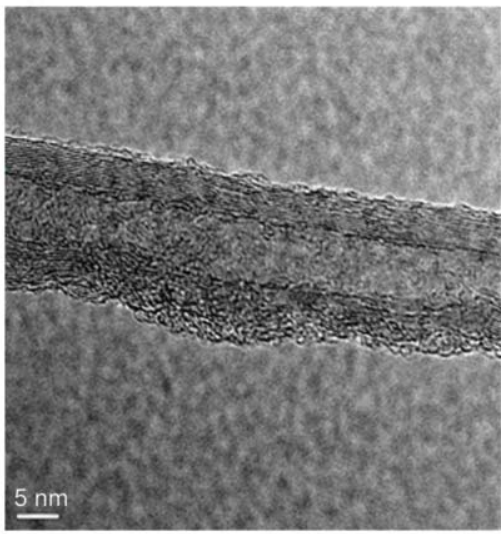

f)

Figure 5. (a) UV-vis spectra of MWPC, PN and PNC; (b) TEM image of EMP0.5, (c) EDX of MWPC showing different elemental composition; (d) TEM image of MWPC with SAED pattern showing full nanohybrid at low resolution; (e) TEM image of MWPC at high resolution showing the presence of CD in the inset and (f) HRTEM image of MWPC with the fringes. 
in inset of Figure $5 \mathrm{c}$. The atomic\%:weight $\%$ is highest for $\mathrm{C}(83.15: 79.14)$ followed by $\mathrm{O}(13.67: 17.33)$ and the lowest for $\mathrm{N}(3.18: 3.53)$. Figure $5 \mathrm{~d}, 5 \mathrm{e}$ and $5 \mathrm{f}$ demonstrated the formation of long fibers of MWPC indicating the proper polymerization of aniline. The average diameter of the nanofiber is 50 $55 \mathrm{~nm}$ and the length is $1600-1700 \mathrm{~nm}$. The presence of CD in MWPC is shown in the inset of Figure 5e. The HRTEM images of MWPC revealed lattice fringes with an average interlayer spacing of $0.323 \mathrm{~nm}$. The image showed the formation of minute agglomeration which indicated the formation of the nanohybrid.

\subsection{Thermal and mechanical properties}

The thermal stabilities of SME and the nanocomposites were evaluated by performing the TG analysis. The thermograms of TG analysis are shown in Figure $6 \mathrm{a}$ and the thermal data obtained from the dTG curves are presented in Table 4. The analysis showed increasing trend with the increasing dose of MWPC in the nanocomposites. This increasing trend can be attributed to the increasing crosslinking density as well as strong secondary interactions offered by the MWPC with the hyperbranched matrix of the nanocomposites. This highly crosslinked network of the thermosets restricts the motion of the molecular chains on exposure to the thermal energy resulting into difficulty in the bond breaking process which in turn imparts greater thermal stability to the polymer matrix. The secondary interactions like polar-polar and hydrogen bonding between the surface functionalities of MWPC and the hydroxyl and epoxy groups of the hyperbranched epoxy as well as the amine groups of the poly(amido amine) offer better crosslinking ability and thermal stability to the thermosetting nanocomposites compared to its pristine thermoset. Therefore, EMP1.5 exhibited better thermostability compared to EMP1, EMP0.5 and SME. The dTG curves also revealed that the degradation consists of two steps, whereas the earlier reported results on MWCNT/epoxy thermograms showed single step degradation process $[30,39]$. The first step was attributed to the aliphatic moieties like monoglyceride, whereas the second step was due to the degradation of the aromatic moieties. The aromatic moieties are thermally more stable and hence, the degradation takes place at higher temperature, in the range of $417-430^{\circ} \mathrm{C}$ for the nanocomposites. The second step is usually a thermo-oxidative reaction process which leads to the char formation and complete degradation of the carbonaceous matter takes place [39]. A comparison of second step of degradation of EMP1 with MWCNT/epoxy nanocomposite (1 wt \% MWCNT)

Table 4. Thermal properties of SME, EMP0.5, EMP1 and EMP1.5.

\begin{tabular}{|ll|c|c|c|c|}
\hline \multicolumn{1}{|c|}{ Parameters } & EMP0.5 & EMP1 & EMP1.5 & SME \\
\hline Onset temperature & {$\left[{ }^{\circ} \mathrm{C}\right]$} & 257 & 260 & 264 & 250 \\
\hline Peak temperature for first step of degradation & {$\left[{ }^{\circ} \mathrm{C}\right]$} & 318 & 329 & 340 & 312 \\
\hline Peak temperature for second step of degradation & {$\left[{ }^{\circ} \mathrm{C}\right]$} & 417 & 424 & 430 & 414 \\
\hline Endset temperature & {$\left[{ }^{\circ} \mathrm{C}\right]$} & 464 & 470 & 478 & 454 \\
\hline
\end{tabular}
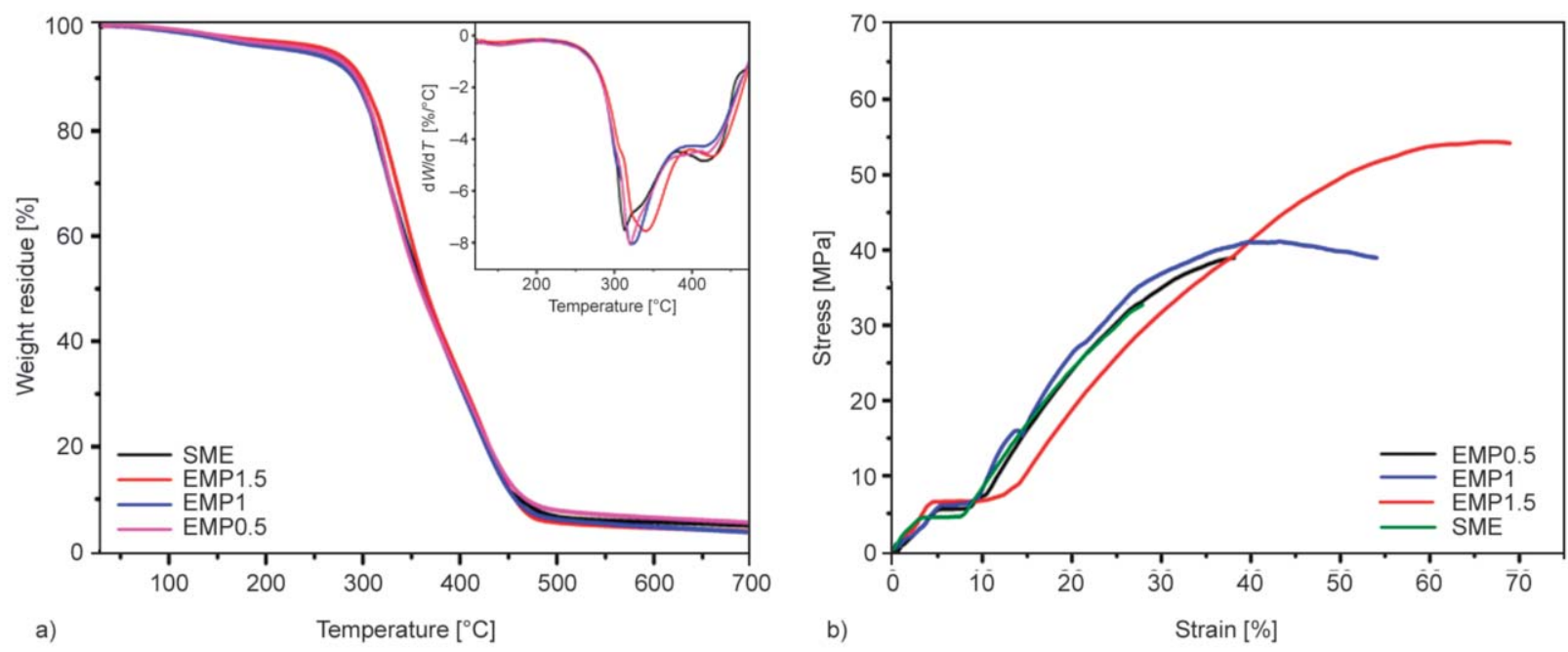

Figure 6. (a) TG thermograms with DTG curves in the inset and (b) stress-strain profiles of EMP0.5, EMP1, EMP1.5 and SME. 
reported by Kumar et al. [26] which indicates an improvement of about $24 \%$.

The mechanical properties of SME, EMP0.5, EMP1 and EMP1.5 demonstrated dose dependent improvement in the tensile strength, scratch resistance, impact resistance and adhesive strength, as given in Table 5 and Figure $6 \mathrm{~b}$. This improvement in the properties is due to the combined effects of several factors like dispersion of MWPC in the polymer matrix, chain entanglement, hydrogen bonding and van der Waals forces as well as the morphology of MWPC which provides strong interfacial interactions with the matrix $[26,38]$. The samples were prepared according to the standard procedure. However, here instead of $\operatorname{dog}$ bone shape the samples are of rectangular shape. In the present study, EMP1.5 demonstrated the highest tensile strength, scratch resistance, impact resistance and adhesive strength compared to EMP1 and EMP0.5. The tensile strength of the nanocomposites even with $0.5 \%$ addition of MWPC increased by $35.7 \%$ compared to SME thermoset. Moreover, with the increasing dose of MWPC from 0.5 to $1.5 \%$ resulted in the improvement of $81.5 \%$ of tensile strength in EMP1.5 compared to EMP0.5. This is due to the combination of PANi and CD functionalization of MWCNT. The different functional groups of the nanomaterial interact with the epoxy matrix including hardener which resulted in the increase in mechanical strength. At the same time, the presence of some sacrificial bonds in the system and extension of molecular chains (hidden chain length) with the slippage of stacked nanotubes under the application of stress provide higher flexibility and elongation. Hence, both strength and elongation enhanced so the thermosets toughened with increasing ductility [38]. However, the apparent flat stress-strain profile (minimal increase of strain) with relatively high strain (4 to $10 \%$ ) may be also due to slippage of the sacrificial bonds and opening of hidden chain length where the amount of energy required is very low as there is breakage of secondary interactions whereas

Table 5. Mechanical properties of SME, EMP0.5, EMP1 and EMP1.5.

\begin{tabular}{|l|r|c|c|c|}
\hline \multicolumn{1}{|c|}{ Properties } & EMP0.5 & EMP1 & EMP1.5 & SME \\
\hline Tensile strength [MPa] & $38 \pm 2.0$ & $42 \pm 1.0$ & $54 \pm 0.5$ & $28 \pm 3$ \\
\hline Elongation at break [\%] & $41 \pm 0.5$ & $40 \pm 3.0$ & $55 \pm 2.0$ & $33 \pm 0$ \\
\hline Scratch hardness [kg] & $9 \pm 0.5$ & $>10$ & $>10$ & $7 \pm 0.5$ \\
\hline Impact strength [kJ/m] & $15.5 \pm 0.5$ & $16.0 \pm 0.7$ & $16.7 \pm 0.6$ & $13.3 \pm 0.5$ \\
\hline Adhesive strength [MPa] & 2722 & 3556 & 4648 & 1660 \\
\hline
\end{tabular}

elongation is very high. The good adhesive strength of the nanocomposites is also due to the good mechanical interlocking with the substrates through physical interactions of the polar epoxy, ether and other hydroxyl groups of the hyperbranched structure, nanohybrid and the poly(amido amine) hardener with the substrates [31]. Thus, the surface functionalized moieties of the nanohybrid strongly interacted with the polar functionalities of the epoxy matrix resulted in homogenous dispersion which further influence the mechanical properties.

\subsection{Chemical resistance}

The chemical resistance in terms of weight change of the films was evaluated and the results are given in Table 6. From this table, it is observed that the films of EMP1.5 exhibited better chemical resistance properties owing to higher content of MWPC and optimum curing as evident from the swelling value (Table 3). Thus, higher amount of MWPC results in higher crosslinking density and that provides excellent chemical resistance through different secondary interactions with the hyperbranched matrix.

\subsection{Anticorrosion properties}

The corrosion measurements were carried out electrochemically to assess the anticorrosion performance of the nanocomposites. The polarization curves for the uncoated and coated samples were tested in different corrosive media (Figure 7). In the corrosive media, the changes of the anodic and cathodic current with potential were recorded and extrapolated up to their point of intercept. Further, different parameters like corrosion potential $\left(E_{\text {corr }}\right)$, corrosion current $\left(I_{\text {corr }}\right)$, polarization resistance $\left(R_{\mathrm{p}}\right)$ and corrosion rate were obtained from the Tafel plot of the polarization curves as given in Equation (2):

$R_{\mathrm{p}}=\frac{b_{\mathrm{a}}+b_{\mathrm{c}}}{2.303\left(b_{\mathrm{a}}+b_{\mathrm{c}}\right)} \cdot I_{\text {corr }}$

where $b_{\mathrm{a}}$ and $b_{\mathrm{c}}$ are anodic and cathodic slopes of Tafel plot, respectively.

Table 6. Weight changes of the nanocomposites in different chemical environments.

\begin{tabular}{|l|c|c|c|l|}
\hline \multicolumn{1}{|c|}{ Medium } & EMP 0.5 & EMP 1 & EMP 1.5 & SME \\
\hline Aq. $\mathrm{HCl} \mathrm{(10 \% )}$ & 0.071 & 0.064 & 0.052 & 0.092 \\
\hline Aq. $\mathrm{NaOH} \mathrm{(5 \% )}$ & 0.058 & 0.047 & 0.033 & 0.088 \\
\hline Aq. $\mathrm{NaCl}(15 \%)$ & 0.031 & 0.028 & 0.015 & 0.052 \\
\hline Water & 0 & 0 & 0 & 0 \\
\hline
\end{tabular}



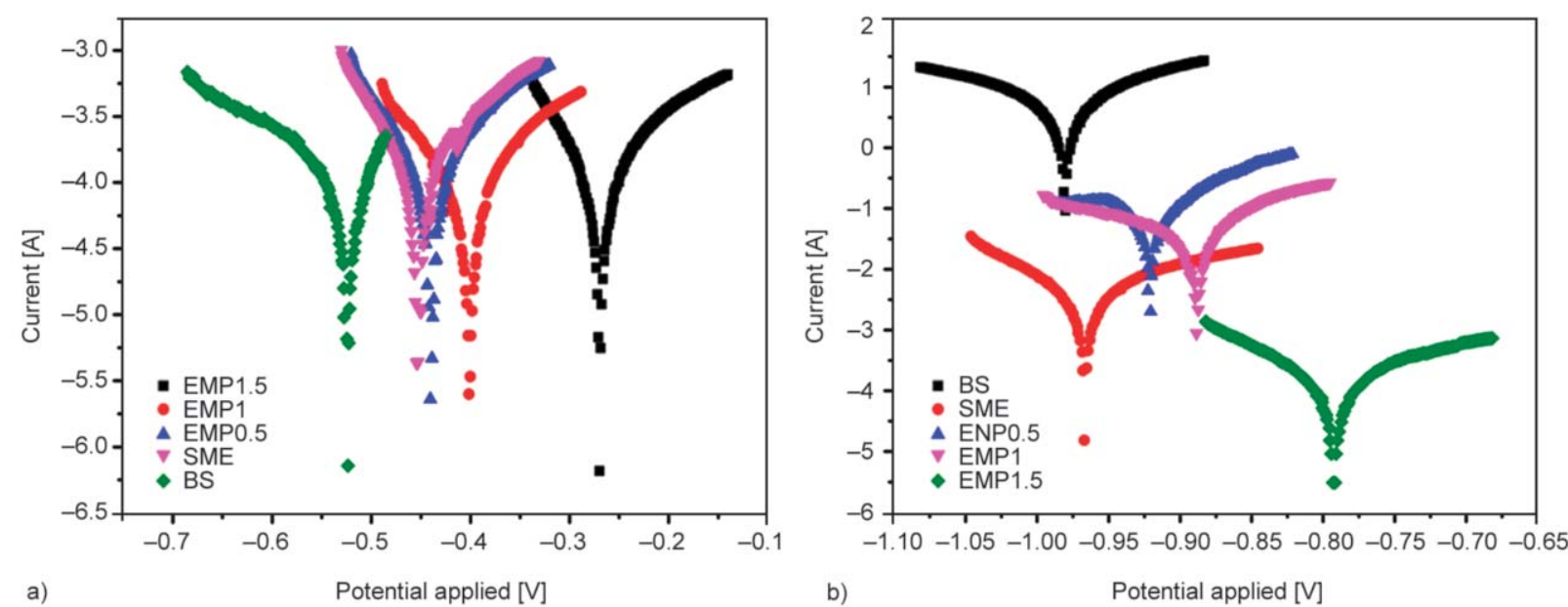

Figure 7. Potentiodynamic studies of the bare metal plate (BS), thermosets of SME and nanocomposites in (a) $3.5 \% \mathrm{NaCl}$ and (b) $3.5 \% \mathrm{HCl}$.

The values of these parameters of the thermosets of nanocomposites and SME are evaluated and tabulated in Table 7. The results showed that EMP1.5 showed better anticorrosion performance compared to the pristine epoxy system. However, anticorrosion performance of the thermosets in $3.5 \% \mathrm{NaCl}$ is better compared to $3.5 \% \mathrm{HCl}$ in all the cases. This is due to the fact that the corrosion rate enhances in the acidic environment, as there are many ether linkages in the matrix. However, these results are found to be better compared to anticorrosive performance of epoxy/MWCNT nanocomposite reported by Kumar et al [26]. This improvement is due to the uniform and stable dispersion of the MWPC nanohybrid in the polymer matrix. The mechanism of corrosion at the metal surface mainly proceeded by the release of electrons due to the oxidation of $\mathrm{Fe}$ and the reduction of $\mathrm{O}_{2}$. Hence, for the smooth propagation of this oxidation-reduction process of corrosion the proper supply of oxygen and water is required. Therefore, it is necessary to have a barrier that would hinder the corrosion process. In this venture, the coating of epoxy on the metal surface was developed to provide sufficient corrosion protection. As a result, the corrosion rate exhibited by $\mathrm{BS}$ is much higher compared to the coated metal plates as shown in Table 7. However, the coating was not sufficient enough to inhibit the penetration of the corrosive ions for a long time. Thus, addition of nanomaterials to the epoxy matrix provides better anticorrosion performance to the metal surface by inducing a tortuous path to the corrosive ions which in turn prolong the corrosion process [40]. Also, the nanohybrid provides large surface area to cathodic reaction and decrease the rate of oxygen molecule reduction [26]. Another factor which influenced the anticorrosion performance is the proper dispersion of the nanohybrid. The nanomaterials have greater tendency to agglomerate which affects the dispersion and induces propagation on the corrosive surface. The study by Kumar et al. [26]

Table 7. Corrosion potential $\left(E_{\text {corr }}\right)$, corrosion current $\left(I_{\text {corr }}\right)$, polarisation resistance $\left(R_{\mathrm{p}}\right)$ and corrosion rate of the bare mild steel plate (BS), thermosetting pristine epoxy and its nanocomposites.

\begin{tabular}{|c|c|c|c|c|c|}
\hline Medium & Sample code & $\begin{array}{c}\text { Corrosion potential, } E_{\text {corr }} \\
{[\mathrm{V}]}\end{array}$ & $\begin{array}{c}\text { Corrosion current, } I_{\text {corr }} \\
{[\mathrm{A}]}\end{array}$ & $\begin{array}{c}\text { Polarisation resistance, } \\
R_{\mathrm{p}}\end{array}$ & $\begin{array}{c}\text { Corrosion rate } \\
{[\mathrm{mpy}]}\end{array}$ \\
\hline \multirow{5}{*}{$3.5 \% \mathrm{NaCl}$} & EMP1.5 & -0.242 & $1.01 \cdot 10^{-8}$ & $2.37 \cdot 10^{5}$ & $4.62 \cdot 10^{-4}$ \\
\hline & EMP1 & -0.389 & $1.17 \cdot 10^{-8}$ & $2.08 \cdot 10^{5}$ & $1.64 \cdot 10^{-5}$ \\
\hline & EMP0.5 & -0.422 & $1.36 \cdot 10^{-8}$ & $1.87 \cdot 105$ & $4.314 \cdot 10^{-3}$ \\
\hline & SME & -0.477 & $3.14 \cdot 10^{-8}$ & $1.654 \cdot 10^{5}$ & 0.1437 \\
\hline & BS & -0.551 & $4.28 \cdot 10^{-6}$ & $0.945 \cdot 10^{2}$ & 2.375 \\
\hline \multirow{5}{*}{$3.5 \% \mathrm{HCl}$} & EMP1.5 & -0.782 & $1.65 \cdot 10^{-5}$ & $1.37 \cdot 10^{3}$ & $6.28 \cdot 10^{-3}$ \\
\hline & EMP1 & -0.882 & $2.17 \cdot 10^{-4}$ & $1.08 \cdot 10^{3}$ & $3.25 \cdot 10^{-3}$ \\
\hline & EMP0.5 & -0.923 & $2.86 \cdot 10^{-4}$ & $0.987 \cdot 10^{3}$ & $2.311 \cdot 10^{-2}$ \\
\hline & SME & -0.965 & $3.08 \cdot 10^{-4}$ & $1.324 \cdot 10^{2}$ & 1.763 \\
\hline & BS & -0.990 & $5.28 \cdot 10^{-2}$ & 0.348 & 3.135 \\
\hline
\end{tabular}


showed that the anticorrosion performance of the nanocomposites decreased with the increase in the percentage of MWCNT in the matrix up to $1 \%$. This is mainly because of the poor dispersion of MWCNT as it agglomerates at higher percentage, which reduces its efficiency for corrosion protection. However, in this study the presence of sufficient polar functionalities of $\mathrm{CD}$ followed by proper polymerization resulted in the formation of sufficient amount of interactions with the polar functionalities of the hyperbranched epoxy. These interactions create a stable and uniform dispersion of the nanohybrid in the epoxy matrix which reflect the dose dependent improvement of anticorrosive performance of the nanocomposites.

\section{Conclusions}

An ex-situ mixing technique demonstrated the stable dispersion of the nanohybrid in sorbitol based hyperbranched epoxy at different weight percentages. Further, an in-situ polymerization of aniline in the presence of MWCNT and CD resulted in the nanohybrid with different polar functionalities. The presence of CD improved the state of dispersion of the nanohybrid in the epoxy matrix. The uniform and stable dispersion has the prime role in the enhancement of performance including corrosion resistance of the nanocomposites. The dose dependent improvements in the mechanical, thermal and anticorrosion properties of the nanocomposites indicate the importance of the nanohybrid. Thus, the present study clearly demonstrated the potential of a renewable resource based nanocomposite to be used as an anticorrosive protection for mild steel surface.

\section{Acknowledgements}

Authors would like to acknowledge HRDG-CSIR for financial support through project Grant No. 22(0759)/17/EMR-II dated 10th October 2017. The authors would also like to thank Sophisticated Analytical Instrument Facility (SAIF), North-Eastern Hills University (NEHU) for helping with the TEM analysis and Sophisticated Analytical Instrumentation Centre (SAIC) Tezpur University for the different analyses used in this study.

\section{References}

[1] Iijima S.: Helical microtubules of graphitic carbon. Nature, 354, 56-58 (1991). https://doi.org/10.1038/354056a0
[2] Léonard F., Talin A. A.: Electrical contacts to one- and two-dimensional nanomaterials. Nature Nanotechnology, 6, 773-783 (2011). https://doi.org/10.1038/NNANO.2011.196

[3] Dubey K. A., Bhardwa Y. K., Chaudhari C. V., Kumar V., Goel N. K., Sabharwal S.: Radiation processed ethylene vinyl acetate-multiple walled carbon nanotube nano-composites: Effect of MWNT addition on the gel content and crosslinking density. Express Polymer Letters, 3, $492-500$ (2009).

https://doi.org/10.3144/expresspolymlett.2009.61

[4] Baker R. T. K.: Catalytic growth of carbon filaments. Carbon, 27, 315-323 (1989).

https://doi.org/10.1016/0008-6223(89)90062-6

[5] Huang S., Woodson M., Smalley R., Liu J.: Growth mechanism of oriented long single walled carbon nanotubes using 'fast-heating' chemical vapor deposition process. Nano Letters, 4, 1025-1028 (2004).

https://doi.org/10.1021/n1049691d

[6] Baddour C. E., Fadlallah F., Nasuhoglu D., Mitra R., Vandsburger L., Meunier J-L.: A simple thermal CVD method for carbon nanotube synthesis on stainless steel 304 without the addition of an external catalyst. Carbon, 47, 313-318 (2009).

https://doi.org/10.1016/j.carbon.2008.10.038

[7] Zhu J., Jia J., Kwong F-L., Ng D. H. L.: Synthesis of bamboo-like carbon nanotubes on a copper foil by catalytic chemical vapor deposition from ethanol. Carbon, 50, 2504-2512 (2012). https://doi.org/10.1016/j.carbon.2012.01.073

[8] Bota P. M., Dorobantu D., Boerasu I., Bojin D., Enachescu M.: Synthesis of single-wall carbon nanotubes by excimer laser ablation. Surface Engineering and Applied Electrochemistry, 50, 294-299 (2014). https://doi.org/10.3103/S106837551404005X

[9] Saito Y.: Nanoparticles and filled nanocapsules. Carbon, 33, 979-988 (1995). https://doi.org/10.1016/0008-6223(95)00026-A

[10] Ajayan P. M.: Nanotubes from carbon. Chemical Reviews, 99, 1787-1800 (1999). https://doi.org/10.1021/cr970102g

[11] Xie X-L., Mai Y-W., Zhou X-P.: Dispersion and alignment of carbon nanotubes in polymer matrix: A review. Materials Science and Engineering R: Reports, 49, 89112 (2005). https://doi.org/10.1016/j.mser.2005.04.002

[12] Savitha P., Swapna Rao P., Sathyanarayana D. N.: Highly conductive new aniline copolymers: Poly(aniline-coaminoacetophenone)s. Polymer International, 54, 12431250 (2005). https://doi.org/10.1002/pi.1834

[13] Mattoso L. H., Faria R. M., Bulhões L. O., MacDiarmid A. G.: Synthesis, doping, and processing of high molecular weight poly(o-methoxyaniline). Journal of Polymer Science Part A: Polymer Chemistry, 32, 2147-2153 (1994). https://doi.org/10.1002/pola.1994.080321117 
[14] Salvetat-Delmotte J-P., Rubio A.: Mechanical properties of carbon nanotubes: A fiber digest for beginners. Carbon, 40, 1729-1734 (2002). https://doi.org/10.1016/S0008-6223(02)00012-X

[15] Yun Y., Dong Z., Shanov V., Heineman W. R., Halsall H. B., Bhattacharya A., Conforti L., Narayan R. K., Ball W. S., Schulz M. J.: Nanotube electrodes and biosensors. Nano Today, 2, 30-37 (2007). https://doi.org/10.1016/S1748-0132(07)70171-8

[16] Saini P., Choudhary V., Singh B. P., Mathur R. B., Dhawan S. K.: Polyaniline-MWCNT nanocomposites for microwave absorption and EMI shielding. Materials Chemistry and Physics, 113, 919-926 (2009).

https://doi.org/10.1016/j.matchemphys.2008.08.065

[17] Cochet M., Maser W. K., Benito A. M., Callejas M. A., Martínez M. T., Benoit J-M., Schreiber J., Chauvet O.: Synthesis of a new polyaniline/nanotube composite: 'in-situ' polymerisation and charge transfer through siteselective interaction. Chemical Communications, 16, 1450-1451 (2001). https://doi.org/10.1039/B104009J

[18] Wang Q., Yao Q., Chang J., Chen L.: Enhanced thermoelectric properties of CNT/PANI composite nanofibers by highly orienting the arrangement of polymer chains. Journal of Materials Chemistry, 22, 17612 17618 (2012).

https://doi.org/10.1039/C2JM32750C

[19] Kumar A. M., Gasem Z. M.: In situ electrochemical synthesis of polyaniline/f-MWCNT nanocomposite coatings on mild steel for corrosion protection in $3.5 \% \mathrm{NaCl}$ solution. Progress in Organic Coatings, 78, 387-394 (2015).

https://doi.org/10.1016/j.porgcoat.2014.07.009

[20] Ghosh D., Giri S., Mandal A., Das C. K.: Supercapacitor based on $\mathrm{H}^{+}$and $\mathrm{Ni}^{2+}$ co-doped polyanilineMWCNTs nanocomposite: Synthesis and electrochemical characterization. RSC Advances, 3, 11676-11685 (2013). https://doi.org/10.1039/C3RA40955D

[21] Li Y-F., Chen C.: Fate and toxicity of metallic and metalcontaining nanoparticles for biomedical applications. Small, 7, 2965-2980 (2011). https://doi.org/10.1002/smll.201101059

[22] Dong Y., Wang R., Li G., Chen C., Chi Y., Chen G.: Polyamine-functionalized carbon quantum dots as fluorescent probes for selective and sensitive detection of copper ions. Analytical Chemistry, 84, 6220-6224 (2012). https://doi.org/10.1021/ac3012126

[23] Song Y., Shi W., Chen W., Li X., Ma H.: Fluorescent carbon nanodots conjugated with folic acid for distinguishing folate-receptor-positive cancer cells from normal cells. Journal of Materials Chemistry, 22, 1256812573 (2012).

https://doi.org/10.1039/C2JM31582C
[24] Gaidukovs S., Medvids A., Onufrijevs P., Grase L.: UVlight-induced curing of branched epoxy novolac resin for coatings. Express Polymer Letters, 12, 918-929 (2018). https://doi.org/10.3144/expresspolymlett.2018.78

[25] Li Y., Huang X., Zeng L., Li R., Tian H., Fu X., Wang Y., Zhong W-H.: A review of the electrical and mechanical properties of carbon nanofiller-reinforced polymer composites. Journal of Materials Science, 54, 10361076 (2019).

https://doi.org/10.1007/s10853-018-3006-9

[26] Kumar A., Ghosh P. K., Yadav K. L., Kumar K.: Thermomechanical and anti-corrosive properties of MWCNT/ epoxy nanocomposite fabricated by innovative dispersion technique. Composites Part B: Engineering, 113, 291-299 (2017).

https://doi.org/10.1016/j.compositesb.2017.01.046

[27] Imani A., Arabi M., Farzi G.: Effect of in-situ oxidative preparation on electrical properties of epoxy/PANi/ MWCNTs nanocomposites. Journal of Materials Science: Materials in Electronics, 27, 10364-10370 (2016). https://doi.org/10.1007/s10854-016-5122-0

[28] Auvergne R., Caillol S., David G., Boutevin B., Pascault J. P.: Biobased thermosetting epoxy: Present and future. Chemical reviews, 114, 1082-1115 (2013). https://doi.org/10.1021/cr3001274

[29] Xia Y., Larock R. C.: Vegetable oil-based polymeric materials: Synthesis, properties, and applications. Green Chemistry, 12, 1893-1909 (2010). https://doi.org/10.1039/C0GC00264J

[30] De B., Gupta K., Mandal M., Karak N.: Biodegradable hyperbranched epoxy from castor oil-based hyperbranched polyester polyol. ACS Sustainable Chemistry \& Engineering, 2, 445-453 (2013).

https://pubs.acs.org/doi/10.1021/sc400358b

[31] Saikia A., Karak N.: Renewable resource based thermostable tough hyperbranched epoxy thermosets as sustainable materials. Polymer Degradation and Stability, 135, 8-17 (2017).

https://doi.org/10.1016/j.polymdegradstab.2016.11.014

[32] Saikia A., Karak N.: Polyaniline nanofiber/carbon dot nanohybrid as an efficient fluorimetric sensor for As (III) in water and effective antioxidant. Materials Today Communications, 14, 82-89 (2018). https://doi.org/10.1016/j.mtcomm.2017.12.020

[33] Rahy A., Sakrout M., Manohar S., Cho S. J., Ferraris J., Yang D. J.: Polyaniline nanofiber synthesis by co-use of ammonium peroxydisulfate and sodium hypochlorite. Chemistry of Materials, 20, 4808-4814 (2008). https://doi.org/10.1021/cm703678m

[34] Cui X., Zhu L., Wu J., Hou Y., Wang P., Wang Z., Yang M.: A fluorescent biosensor based on carbon dots-labeled oligodeoxyribonucleotide and graphene oxide for mercury (II) detection. Biosensors and Bioelectronics, 63, 506-512 (2015). https://doi.org/10.1016/j.bios.2014.07.085 
[35] Wang Z., Zhao G-L.: Microwave absorption properties of carbon nanotubes-epoxy composites in a frequency range of 2-20 GHz. Open Journal of Composite Materials, 3, 17-23 (2013).

https://doi.org/10.4236/ojcm.2013.32003

[36] Deka H., Karak N., Kalita R. D., Buragohain A. K.: Biocompatible hyperbranched polyurethane/multi-walled carbon nanotube composites as shape memory materials. Carbon, 48, 2013-2022 (2010)

https://doi.org/10.1016/j.carbon.2010.02.009

[37] Bayan R., Karak N.: Renewable resource derived aliphatic hyperbranched polyurethane/aluminium hydroxide-reduced graphene oxide nanocomposites as robust, thermostable material with multi-stimuli responsive shape memory features. New Journal of Chemistry, 41, 8781-8790 (2017).

https://doi.org/10.1039/C7NJ01841J
[38] Ghosh T., Karak N.: Multi-walled carbon nanotubes reinforced interpenetrating polymer network with ultrafast self-healing and anti-icing attributes. Journal of Colloid and Interface Science, 540, 247-257 (2019). https://doi.org/10.1016/j.jcis.2019.01.006

[39] Zotti A., Zuppolini S., Borriello A., Zarrelli M.: Thermal properties and fracture toughness of epoxy nanocomposites loaded with hyperbranched-polymers-based core/shell nanoparticles. Nanomaterials, 9, 418/1418/14 (2019). https://doi.org/10.3390/nano9030418

[40] Pathan S., Ahmad S.: Synthesis, characterization and the effect of the s-triazine ring on physico-mechanical and electrochemical corrosion resistance performance of waterborne castor oil alkyd. Journal of Materials Chemistry A, 1, 14227-14238 (2013). https://doi.org/10.1039/C3TA13126B 